without the side effects of a long-acting spinal block and makes it more favourable in modern enhanced recovery programmes.

\section{HEMODYNAMIC STABILITY BETWEEN SPINAL AND GENERAL ANAESTHESIA IN PATIENT UNDERGOING PRIMARY TOTAL KNEE ARTHROPLASTY: A RETROSPECTIVE STUDY}

${ }^{1} \mathrm{~T}$ Jeandin*, ${ }^{1} \mathrm{E}$ Albrecht, ${ }^{2} \mathrm{~J}$ Wegrzyn, ${ }^{1} \mathrm{M}$ Cachemaille. ${ }^{1}$ Department of Anaesthesia, Lausanne University Hospital and University of Lausanne, Lausanne, Switzerland; ${ }^{2}$ Department of Orthopaedics and Traumatology, Lausanne University Hospital and University of Lausanne, Lausanne, Switzerland

\subsection{6/rapm-2021-ESRA.51}

Background and Aims Total knee arthroplasty is a very common surgical procedure in daily practice and its number is constantly increasing. Some studies have reported that general anaesthesia was associated with greater hemodynamic instability, but this paradigm has since been disputed. The aim of this study is to evaluate intraoperative hemodynamic stability during total knee arthroplasty according to the type of anaesthesia. The hypothesis is that hemodynamic stability is better preserved during spinal anaesthesia (SA) compared to general anaesthesia (GA).

Methods Adults undergoing primary total knee arthroplasty were retrospectively selected over a period of 10 years. Primary outcome was the presence of a hemodynamic instability defined by a norepinephrine infusion started when the variation of patient's blood pressure exceeded 30\% of its baseline value for more than 5 minutes. Secondary outcomes included mean intraoperative dose of ephedrine, mean blood loss, and mean volume of fluid administered. Demographic data and anaesthetic strategy were extracted. Patients receiving SA versus GA were compared for the different variables.

Results Demographic data are displayed in table 1. Patients under SA received less ephedrine $(p<0.0001)$, less infusion of norepinephrine $(\mathrm{p}<0.0001)$ and less intraoperative fluids $(p<0.0001)$ than patients under GA, while blood loss was similar between groups $(\mathrm{p}=0.29)$ (table 2$)$.

Abstract 51 Table 1 Baseline characteristics of all patients according to the Anaesthetic Strategy. (Data presentation either by the absolute number and its percentage for categorical values (Pearson test) or by the mean and the 95\% confidence interval for continuous values (Student test))

\begin{tabular}{|c|c|c|c|c|}
\hline & $\begin{array}{l}\text { General Anaesthesia } \\
\qquad(n=685,41.0 \%)\end{array}$ & $\begin{array}{l}\text { Spinal Anaesthesia } \\
\text { (n=984, 59.0\%) }\end{array}$ & $\begin{array}{c}\text { Total } \\
\text { (n=1669, 100.0\%) }\end{array}$ & $p$-value \\
\hline $\begin{array}{l}\text { Sex } \\
\text { Female }\end{array}$ & $446(64.9)$ & 555 (56.5) & $1001(60.0)$ & \\
\hline Male & $241(35.1)$ & $427(43.5)$ & $668(40.0)$ & 0.0006 \\
\hline Age [years] & $\begin{array}{c}69 \\
68-69\end{array}$ & $\begin{array}{l}70 \\
69-70\end{array}$ & $\begin{array}{c}69 \\
69-70\end{array}$ & 0.02 \\
\hline Height $[\mathrm{cm}]$ & $\begin{array}{c}165 \\
165-166\end{array}$ & $\begin{array}{c}167 \\
166-167\end{array}$ & $\begin{array}{c}166 \\
166-167\end{array}$ & 0.21 \\
\hline Weight [kg] & $\begin{array}{c}82 \\
81-83\end{array}$ & $\begin{array}{c}83 \\
82-84\end{array}$ & $\begin{array}{c}83 \\
82-83\end{array}$ & 0.32 \\
\hline $8 \mathrm{MI}\left[\mathrm{kg} / \mathrm{m}^{2}\right]$ & $\begin{array}{c}30 \\
30-30\end{array}$ & $\begin{array}{c}30 \\
29-30\end{array}$ & $\begin{array}{c}30 \\
30-30\end{array}$ & 0.68 \\
\hline $\begin{array}{l}\text { ASA class } \\
1 \\
\text { II } \\
\text { III } \\
\text { IV }\end{array}$ & $\begin{array}{c}28(4.1) \\
469(68.3) \\
189(27.5) \\
1(0.2)\end{array}$ & $\begin{array}{c}52(5.3) \\
631(64.3) \\
297(30.2) \\
3(0.2)\end{array}$ & $\begin{array}{c}80(4.8) \\
1100(65.9) \\
486(29.1) \\
3(0.2)\end{array}$ & 0.34 \\
\hline $\begin{array}{l}\text { Nervous Block } \\
\text { No } \\
\text { Yes }\end{array}$ & $\begin{array}{c}25(3.6) \\
660(96.4)\end{array}$ & $\begin{array}{c}9(0.9) \\
975(99.1)\end{array}$ & $\begin{array}{c}34(2.0) \\
1635(98.0)\end{array}$ & $<0.0001$ \\
\hline $\begin{array}{l}\text { Surgical infiltration } \\
\text { No } \\
\text { Yes }\end{array}$ & $\begin{array}{l}532(77.7) \\
153(22.3) \\
\end{array}$ & $\begin{array}{l}564(57.3) \\
420(42.7)\end{array}$ & $\begin{array}{c}1096(65.7) \\
573(34.3)\end{array}$ & $<0.0001$ \\
\hline
\end{tabular}

Abstract 51 Table 2 Intraoperative data according to the Anaesthetic Strategy. (Data presentation either by the absolute number and its percentage for categorical values) Pearson test) or by the mean and the $95 \%$ confidence interval for continuous values (Student test))

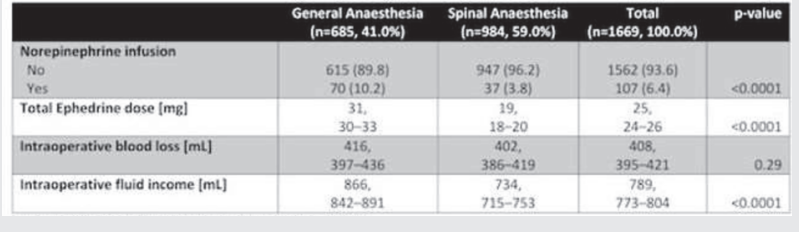

Conclusions Patients under SA have a better intraoperative hemodynamic stability, as they required less vasopressors than patients under GA.

\section{LOSS OF CONSCIOUSNESS WITHOUT HEMODYNAMIC AND RESPIRATORY DISTURBANCES FOLLOWING SPINAL ANESTHESIA FOR CESAREAN SECTION: A CASE REPORT}

AAGPS Jaya*, AR Tantri, P Pryambodho. Universitas Indonesia/Dr. Cipto Mangunkusumo Hospital, Department of Anesthesiology and Intensive Care, Faculty of Medicine, Jakarta Pusat, Indonesia

\subsection{6/rapm-2021-ESRA.52}

Background and Aims Cesarean section is commonly performed under spinal anesthesia, as it is simple, rapid, safe, effective, and maintains maternal awareness. Total spinal anesthesia is a known complication manifested by loss of consciousness, severe bradycardia, hypotension, and respiratory arrest. We describe a case of an unconscious event following spinal anesthesia in the presence of stable hemodynamic and respiratory function.

Methods 21-year-old parturient, $150 \mathrm{~cm}, 60 \mathrm{~kg}, 40-41$ weeks of gestation, primigravida, and premature rupture of membrane, scheduled for cesarean section. The patient was assessed with physical status ASA 2 (pregnancy), without any other medical illness. Spinal anesthesia was performed uneventfully, using a $27 \mathrm{G}$ spinal needle, at L3/L4 interspinous space, paramedian approach, with the patient in the left lateral decubitus position. Bupivacaine $0.5 \%$ heavy 12.5 mg was administered after cerebrospinal fluid flow was confirmed.

Results When obstetrician would make an incision, approximately 5 minutes following spinal anesthesia, the patient was unresponsive, and her pupil dilated. Hemodynamic status was stable, and no respiratory depression was observed. There were no complaints before the loss of consciousness. Supportive management was done, and the patient regained consciousness one and a half-hour after spinal anesthesia. The rostral spread of inadvertent injection of local anesthetics into subdural space is speculated.

Conclusions Loss of consciousness following spinal anesthesia in non-sedated patients with stable hemodynamic and respiratory function is uncommon, but it should be considered, and resuscitation equipment must always be available. When recognized, supportive treatment, especially airway management, is needed until patient regains consciousness, in accordance with the local anesthetic duration of action. 